Ophthalmology for twelve months in connection with Hospitals and Institutions approved by the Board, and that they either have already obtained Certificates at Oxford of Courses of study in Ophthalmology, Physiological Optics, and the Anatomy of the Eye, or have served for a period of not less than twelve months since August, 1914, in the Forces of His Majesty or his Allies or the United States of America.

The examiners appointed for this year are Dr. G. Mackay, of Edinburgh, and Lieut.-Colonel R. H. Elliot, of London.

Most of the teaching staff having been engaged on military work, it has been found impossible to hold the ordinary two months' course of instruction at the University this year, and we think the authorities are to be congratulated on throwing the examination open for this occasion to those who have been serving their countries in the war, as it will afford an opportunity to many men to take this qualification before returning to their homes or settling down to regular practice again.

In 1920 and subsequent years the ordinary regulations and requirements, as set out in the Statute and Regulations, come into force again.

Anyone requiring any further information is advised to apply to the Assistant Registrar, University Registry, Oxford, from whom all details can be obtained.

\title{
Blindness from Ophthalmia Neonatorum
}

The National Committee for the Prevention of Blindness (New York), has issued a new edition of its " Summary of State Laws and Rulings relating to the Prevention of Blindness from Babies' Sore Eyes" (publication No. 9 of the series). A perusal of its contents shows that there has been a great advance in legislation since the first edition of this pamphlet appeared in 1916. The material is briefly summarized below:

1. The reporting of babies' sore eyes to the local health officer or to

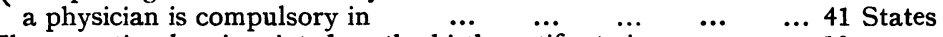

2. The reporting law is printed on the birth certificate in $\quad \ldots .4610 \quad$,

3. Local health officers are authorized and required to secure medical attention for uncared-for cases, or to warn parents of the dangers

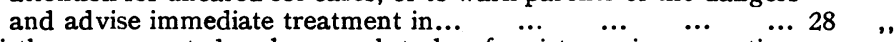

4. Births are reported early enough to be of assistance in prevention

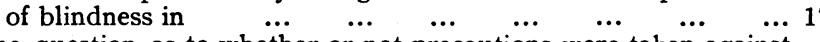

5. The question as to whether or not precautions were taken against ophthalmia neonatorum is included on the birth certificate in ... 19 ,

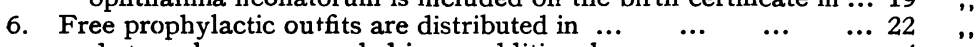

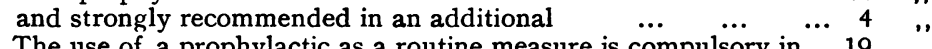

7. The use of a prophylactic as a routine measure is compulsory in... 19 "

8. Popular educational leaflets, relating in whole or in part to prevention of infantile blindness, are distributed by State

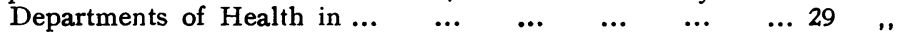


Of these various measures the National Committee regards as the most important the compulsory notification to the local health officers of all cases of ophthalmia, so that medical attention can then be provided for all uncared-for cases of the disease. This implies an early notification of all births, as well as authorization of the health officer to secure necessary medical and nursing attention. Notification is adopted in all the States but two, but not early notification-ten days seems to be the general rule. In twentyeight of forty-nine States provision is made to meet the latter.

\section{Photometry}

An interesting but necessarily incomplete account of some recent military uses of photometry appears in the Illuminating Engineer (November and December, 1918). Two Committees of the Society had been, appointed to deal with the illuminating value of flares, parachute lights, etc., and the brightness of self-luminous radioactive paint. The main lines of investigation obviously presented the greatest possible contrast. In the one case the source of light was of very short duration, great intensity, and considerable fluctuation; while in the other the luminosity was of low intensity which very gradually declined and required a long period of time for its study. For the study of the value of flare lights a photometer was required which should be portable, self-contained, direct reading, and purely inspectional without requiring any manipulation or adjustment during use. Such a photometer was designed by Mr. J. G. Clark which proved satisfactory in use. A full account of this simple instrument as also of another satisfactory model from the design of Mr. J. S. Dow is given by Mr. A. P. Trotter in the Journal referred to. It was satisfactory to find that careful tests showed that our flares were in no way inferior to those used by the enemy. The photometer employed in these tests has the advantage of being visible to a number of observers at the same time, and could be employed for demonstration purposes in testing ordinary illuminating methods for factory and school lighting, etc. The testing of luminous compositions gave very valuable results which incidentally resulted in a considerable saving of the costly radio-active paints. The tests were made in duplicate by Messrs. Dow and Clinton. The principle of the method adopted consisted in the viewing of the luminous sample through a very small slit in a white surface illuminated by a glow lamp and screened by a suitable green glass filter. 